\title{
O INSTITUTO DE ÍNDIAS DE ALTO \\ ALEGRE: CATEQUESE, INSTRUÇÃO \\ E REINVENÇÃO INDÍGENA \\ (MARANHÃO, SÉCULO XIX/XX)
}

El Instituto de Indias de Alto Alegre:

catequesis, instrucción y reinvención indígena

(Maranhão, siglos $X I X / X X)$

\section{The Indies Institute of Alto Alegre: \\ catechesis, instruction and indigenous reinvention (Maranhão, XIX/xx century)}

\author{
Maria Aparecida Corrêa Custódio \\ Universidade Federal do Maranhão (campus Imperatriz) \\ Correo-e: mac.custodio@ufma.br
}

Recibido: 20 de agosto de 2020. Envío a informantes: 3I de agosto de 2020.

Aceptación definitiva: 17 de marzo de 202I

Resumo: Este artigo está circunscrito a um período (republicano), um objeto (o Instituto de Índias) e um lugar (colonia indígena de Alto Alegre, Nordeste do Brasil). Tem como objetivo reconstituir parcela da história do instituto de educação para meninas indígenas criado pelos Frades Menores Capuchinhos da província religiosa de Milão (Itália). Analisa os significados desse trabalho catequético-pedagógico e sua recepção pela comunidade indígena a partir de indícios produzidos no Arquivo Histórico da Província Nossa Senhora do Carmo de São Luís do Maranhão.

Palavras Chave: educação; religião; povos indígenas; Amazônia; Brasil.

REsUmen: Este artículo se limita a un período (republicano), un objeto (el Instituto de Indias) y un lugar (colonia indígena de Alto Alegre, nordeste de Brasil). 


\section{$4 \mathrm{IO}$ \\ O INSTITUTO DE ÍNDICAS DE ALTO ALEGRE: \\ CATEQUESE, INSTRUÇÃO E REINVENÇÃO INDÍGENA (MARANHÃO, SÉCULO XIX/XX) MARIA APARECIDA CORRÊA CUSTÓDIO}

Tiene como objetivo reconstruir parte de la historia del instituto de educación para niñas indígenas desarrollado por los Frailes Menores Capuchinos de la provincia religiosa de Milán (Italia). Analiza los significados de esta labor catequético-pedagógica y su acogida por parte de la comunidad indígena desde evidencias producidas en el Archivo Histórico de la Provincia Nossa Senhora do Carmo de São Luís de Maranhão.

Palabras Clave: educación; religión; pueblos indígenas; Amazonia; Brasil.

AвSTRACT: This article is circumscribed to a period (republican), an object (the Institute of Indies) and a place (colony of Alto Alegre, Northeast Brazil). It aims to reconstruct part of the history of the institute of education for indigenous girls created by the Capuchin Friars Minor of the religious province of Milan (Italy). It analyzes the meanings of this catechetical-pedagogical work and its reception by the indigenous community based on evidence produced in the Historical Archive of the Nossa Senhora do Carmo Province of São Luís do Maranhão.

KEY WORDS: education; religion; indigenous peoples; Amazon; Brazil.

\section{Introdução}

$\mathrm{N}$

O BRAsil ATUAL (fins da segunda década do século XXI), a discussão sobre o lugar dos povos indígenas na sociedade brasileira está recolocada no contexto de novos problemas político-ideológicos diante da proposta do governo de promover a mineração e expansão do agronegócio em terras indígenas, além de ter paralisado a demarcação dos territórios. Trata-se de um momento difícil para o movimento indígena, porém propício para se fazer uma releitura dessa história e de suas apropriações referentes aos projetos de integração nacional. Este artigo contribui com parte dessa releitura à medida que reconstitui parcela da história do instituto de educação para meninas indígenas de Alto Alegre, o qual fazia parte de uma colônia fundada pelos frades capuchinhos (da província religiosa de Milão/Itália) na região de Barra do Corda, Centro-Sul do estado do Maranhão (Nordeste do Brasil).

A Colônia de Alto Alegre (ou Colônia Indígena de São José da Providência em Alto Alegre como também é chamada na documentação) estava vinculada à Missão do Maranhão (I894-1922), que abrangia atividades como a catequese e civilização dos povos indígenas no contexto da política indigenista dos primórdios da República no Brasil. Na época, o governo central havia responsabilizado os estados pela catequese e civilização dos índios por meio do Decreto n. 7, de 20 de novembro de i889. No Maranhão, essa tarefa foi delegada aos capuchinhos lombardos (assim chamados porque eram da Lombardia, Norte da Itália) e perdurou até a instalação de um posto do Serviço de Proteção aos Índios (SPI) em Barra do Corda, em fins de I9I3. A partir do SPI, os capuchinhos «nunca iriam receber 
permissão para criar missão e sim apenas para fazer desobrigas ou visitas às aldeias» (Gomes, 2002: 276).

$\mathrm{Na}$ verdade, os capuchinhos lombardos chegaram ao Brasil em 1892 a convite do governo brasileiro e com apoio da Nunciatura Apostólica a fim de realizarem uma missão de civilização dos índios, colonização do interior e proteção das fronteiras da Amazônia (Meireles, 1977: 264) ${ }^{\text {. }}$. Coube ao frei Carlo de São Martino Olearo (um líder inato que depois foi nomeado Superior da Missão do Maranhão) se articular com dom Antônio Cândido de Alvarenga (bispo do Maranhão) para os capuchinhos trabalharem na sua Diocese, que representava um caminho para se chegar a toda região amazônica.

Os capuchinos se instalaram em São Luís e interiorizaram a ação pastoral com missões ambulantes. Simultaneamente iniciaram a missão indígena na região da paróquia de Barra do Corda onde o bispo do Maranhão os havia destinado. Essa igreja se encontrava sem padre há mais de 20 anos. Para os capuchinhos, Barra do Corda era um lugar emblemático, pois abrigou a colônia indígena Dois Braços na qual frei Giuseppe Maria de Loro Piceno foi o primeiro diretor em i874. Ele ficou até I882, se ausentou entre 1878 e I879 e foi substituído pelo Frei Antonino de Reschio (Gomes, 2002: 252-253).

Nesse lugar frei Carlo idealizou a criação de um instituto de educação para meninos indígenas (na cidade), uma colônia indígena e nela um instituto feminino. Para implantar o projeto ele teve apoio do secretário das Missões (frei Antonino de Reschio), do bispo e dos confrades, contando ainda com a adesão de parte dos indígenas e auxílio financeiro do governo do estado do Maranhão. No entanto, Carlo enfrentou oposição do frei Mansueto de Peveranza que era contra a proposta de criação dos institutos de índios e da colônia indígena. Ele queria que o missionário residisse na aldeia, abrisse ali uma escola e realizasse a catequese (Nembro, I957: 64). Apesar do historiador Nembro elogiar o frei Mansueto não se pode esquecer da representação de missão no século XIX: era importante implantar a religião como caminho de civilização mesmo que isso afetasse a estrutura sociocultural nativa. "Tal era, sem dúvida, a grande lição que a experiência jesuítica transmitira aos seus sucessores»(Gomes, 2002: 267). Por todas essas razões, o ponto de tensão da missão realizada no Maranhão foi o trabalho com os indígenas. Tanto é que a Colônia de Alto Alegre e seu instituto de meninas indígenas foram destruídos no contexto de uma rebelião ocorrida em I90I.

A Nunciatura Apostólica intermediou o contato do governo brasileiro com a Ordem capuchinha. A Nunciatura é a principal representação diplomática do Vaticano no Brasil, sendo equivalente a uma embaixada da Santa Sé. Na época, a sede da Nunciatura ficava na cidade do Rio de Janeiro. Hoje está em Brasília. 
O INSTITUTO DE ÍNDICAS DE ALTO ALEGRE:

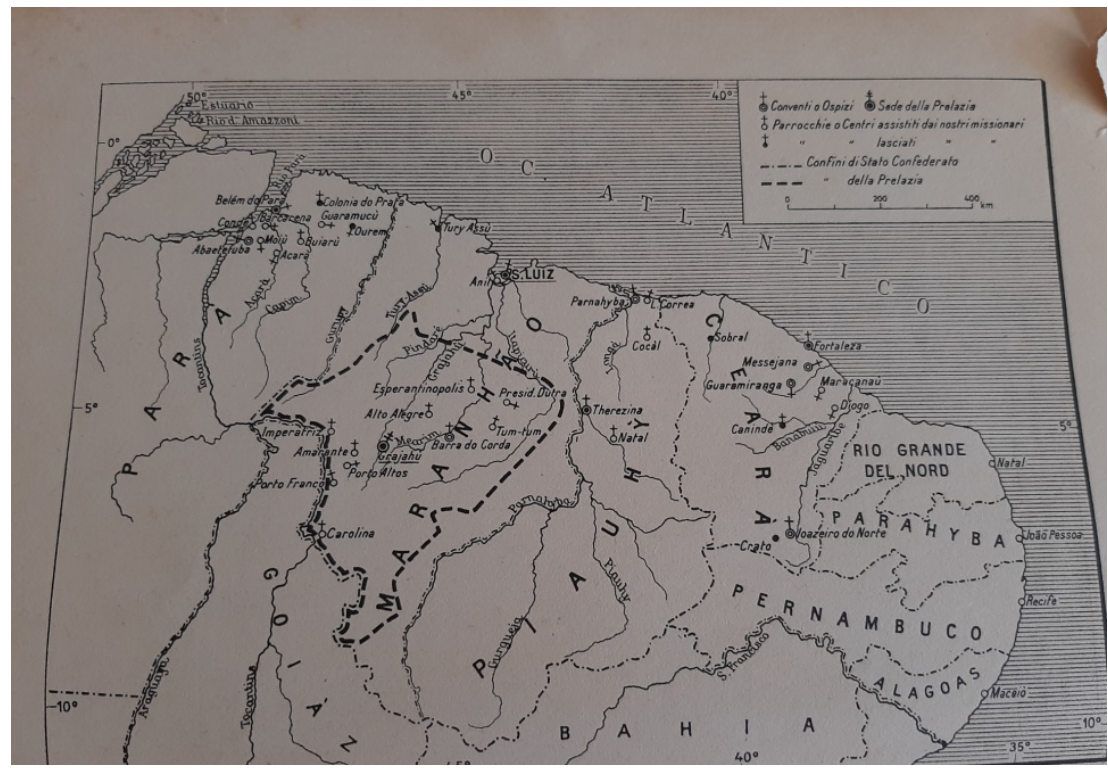

Fonte: Nembro (1957: 12).

Para compreender os eventos supracitados produzimos dados no Arquivo Histórico da Província Nossa Senhora do Carmo de São Luís². Para analisar os dados produzidos dialogamos com a literatura especializada sobre o povo Tentehar, maioria da região de Alto Alegre e, portanto, da missão capuchinha ${ }^{3}$. Para analisar a apropriação dos indígenas e sua relação com os missionários utilizamos A invenção do cotidiano de Michel de Certeau (2009).

Michel de Certeau se interessa pelas operações dos usuários ou consumidores dos produtos oferecidos pelo mercado de bens culturais. $\mathrm{O}$ foco de sua investigação são as maneiras diferentes do fazer cotidiano desses usuários que se apropriam dos bens culturais e cujas práticas anônimas precisam ser conhecidas e sistematizadas. Neste artigo, indagamos como os indígenas se apropriaram da

2 O trabalho foi realizado em diversas etapas segundo o cronograma do Projeto de Pesquisa que recebeu auxílio financeiro da Fundação de Amparo à Pesquisa e ao Desenvolvimento Científico e Tecnológico do Maranhão (FAPEMA).

3 A designação Tentehar é a mais usada atualmente pelas lideranças indígenas dessa etnia, sendo também adotada pela literatura mais recente, embora muitos estudiosos ainda usem Tenetehara. Trata-se de uma autodesignação que quer dizer «o ser íntegro, gente verdadeira». No Brasil, o povo Tentehar é mais conhecido como Guajajara, que significa «dono do cocar», termo provavelmente que lhes foi dado pelos Tupinambá da Ilha de São Luís (GOMES, 2002: 47, 49). Sua língua pertence à família Tupi-Guarani. Na atualidade, é um dos povos indígenas mais numerosos do Brasil, habitando em II Terras Indígenas, todas situadas no Maranhão (Instituto Socioambiental, 2020). 
O INSTITUTO DE ÍNDICAS DE ALTO ALEGRE:

CATEQUESE, INSTRUÇÃO E REINVENÇÃO INDÍGENA (MARANHÃO, SÉCULO XIX/XX)

MARIA APARECIDA CORRÊA CUSTÓDIO

Colônia de Alto Alegre. Conjecturamos que eles fizeram uso de muitas táticas para se apropriar dos bens culturais da missão capuchinha.

A tática não dispõe de base onde capitalizar seus proveitos, preparar suas expansões e assegurar uma independência em face das circunstâncias. [...] Ao contrário, pelo fato de seu não lugar, a tática depende do tempo, vigiando para «captar no voo» possibilidades de ganho. O que ela ganha, não guarda. Tem constantemente que jogar com os acontecimentos para os transformar em "ocasiões». Sem cessar, o fraco deve tirar partido de forças que lhe são estranhas. Ele o consegue em momentos oportunos onde combina elementos heterogêneos [...], mas a sua síntese intelectual tem por forma não um discurso, mas a própria decisão, ato e maneira de aproveitar a «ocasião». (Certeau, 2009: 45-46)

Certeau afirma que muitas práticas cotidianas são táticas e grande parte representa uma pequena vitória sobre o mais forte. É assim que percebemos a trajetória dos indígenas em Alto Alegre: seus corpos em movimento percorreram trilhas, construíram práticas, procederam de forma tática ao longo de vários eventos significativos. Nesse movimento, os indígenas se depararam e se confrontaram com os missionários que por estarem em um lugar próprio (de comando da missão) fizeram uso de muitas estratégias.

A estratégia postula um lugar suscetível de ser circunscrito como algo próprio e ser a base de onde se podem gerir as relações com uma exterioridade de alvos ou ameaças (os clientes ou os concorrentes, os inimigos, o campo em torno da cidade, os objetivos e objetos da pesquisa etc.). Como na administração de empresas, toda racionalização «estratégica» procura em primeiro lugar distinguir de um «ambiente» um «próprio», isto é, o lugar do poder e do querer próprios.

[...] as estratégias são ações que, graças ao postulado de um lugar de poder [a Missão] elaboram lugares teóricos - sistemas, doutrinas e discursos totalizantes capazes de articular um conjunto de lugares físicos onde as forças se distribuem. (Certeau, 2009: 93 e 96, grifos do original)

Como o poder é relacional, verificamos que os indígenas usaram estratégias para fazer valer seus princípios e tradições quando ocuparam um lugar próprio por ocasião da rebelião que destruiu a Colônia de Alto Alegre e sua obra mais notável, o instituto de educação para meninas indígenas.

\section{A Colônia de Alto Alegre (I896-190I)}

Em I896, os capuchinhos articularam a fundação de uma colônia indígena em um lugar chamado Alto Alegre (zona rural), situado entre as cidades de Barra do Corda e Grajaú. Eles já haviam criado um instituto de educação para meninos indígenas em Barra do Corda, em I895. Desde fevereiro de I896 tinham anuência do governo do Maranhão para cuidar da educação das crianças indígenas. Para isso, passaram a receber um parco subsídio anual. 


\section{O INSTITUTO DE ÍNDICAS DE ALTO ALEGRE:

A Crônica da Colônia Indígena de São José da Providência em Alto Alegre, capturada no estudo de Merlatti (200I), relata que o objetivo principal dessa missão era "cristianizar os pobres índios», cabendo a cada missionário ter "paciência no ato de educar e na ação de convencimento» dos indígenas. Dentro desse objetivo maior, havia três finalidades específicas:

$\left.\mathrm{I}^{\circ}\right)$ Convencer os índios a abandonarem as suas aldeias para viverem de forma civilizada e religiosamente agregados na colônia; $2^{\circ}$ ) Educar as meninas e também os meninos cujos pais residem na colônia e não queiram enviá-los para o Colégio de Barra; $3^{\circ}$ ) Promover a agricultura para prover de mantimentos os colégios, como também para acostumar os índios ao trabalho. (Merlatti, 200I: 57)

A Colônia de Alto Alegre deu continuidade aos trabalhos iniciados em Barra do Corda e contribuiu com a sua manutenção por meio do fornecimento de produtos agrícolas. Simultaneamente contribuiu com a conversão indígena pelo trabalho agrícola na suposição de que era preciso fixar os povos originários para que eles deixassem a vida errante pelas matas (Monza, 2016: 60). E abriu escola para os meninos indígenas cujos pais não quisessem enviá-los para o Instituto de Barra do Corda. De qualquer forma, a Colônia de Alto Alegre representou um empreendimento para os indígenas. Prova disso é o registro de sua participação ativa na inauguração da colônia.

O padre Carlo determinou inaugurar a nova colônia de Alto Alegre no primeiro dia de junho de i896. Não há como dizer do entusiasmo provocado pelo anúncio do empreendimento. A notícia se espalhou como um raio, e, no dia da inauguração da colônia, o padre Carlo e seus missionários viram-se rodeados por uma multidão que tinha vindo da Barra do Corda, de Grajaú, e de todos os arredores para assistir à cerimônia. O que, porém, deu maior relevo à solenidade e constituiu a sua verdadeira marca foi o fato de muitos selvagens das aldeias vizinhas terem comparecido, com sua indumentária característica, para tomar parte ativa na inanguração. [...] Grande foi o júbilo daquele dia. Os selvagens, carregando ramos de árvores de todo tipo, voltaram às suas aldeias anunciando a chegada do Grande Pai a seu meio. (Monza, 2016: 47-48, grifos nossos)

Com essa recepção, a colônia inicialmente agregou algumas famílias dos povos Tentehar e Timbira de aldeias próximas4. Agregou também famílias cristãs que aderiram ao projeto sob a condição de seguirem as normas de convivência, trabalho e religiosidade impostas pelos capuchinhos. Não se sabe o número exato de pessoas, mas até agosto de 1897 a historiografia capuchinha registrou a existência de três famílias indígenas morando na colônia. Em dezembro, mais II foram agregadas.

4 Na documentação capuchinha, os povos mais citados são os Guajajara (Tentehar), Canela e Timbira (sem fazer distinção de etnia). Os povos Timbira incluíam os Canela Apanyekrá, Canela Ramkokamekrá, Kricati, Gavião Parkatejê, Gavião Pykopjê, Krahô e Krinkatí (Instituto Socioambiental, 2020). 
O INSTITUTO DE ÍNDICAS DE ALTO ALEGRE:

CATEQUESE, INSTRUÇÃO E REINVENÇÃO INDÍGENA (MARANHÃO, SÉCULO XIX/XX)

MARIA APARECIDA CORRÊA CUSTÓDIO

No final de i898, frei Rinaldo de Paullo (à época Superior da Missão do Maranhão) se alegrava com os resultados de Alto Alegre mencionando em seus escritos a existência de i8 famílias. Sem contar os índios que apenas trabalhavam na plantação e permaneciam de três a cinco meses na colônia, oportunidade para receberem instrução e catequese. Nesse período, Frei Rinaldo calculou uma média de 250 pessoas habitando a colônia (Nembro, 1957: II7). Os números evidenciam a adesão tática dos indígenas dispostos a aproveitar a ocasião para captar uma possibilidade de ganho que, naquele momento, era a fartura de produtos agrícolas da colônia (a historiografia capuchinha sugere que era o polo de atração de indígenas e colonos cristãos). Outra possibilidade de ganho era a escola de alfabetização.

No início, a inserção gradativa dos indígenas foi vista com bons olhos pelo frei Celso de Uboldo, em carta dirigida ao Ministro Geral (Superior da Ordem), escrita no dia 16 de janeiro de I898, logo após ter sido eleito diretor da Colônia de Alto Alegre.

A conversão dos índios parece bem encaminhada; mais famílias me pediram a sua admissão na nova comunidade cristã; respondi que aguardassem porque, como ensina o grande mestre da Missão, o imortal Cardeal Massaia, as conversões em massa mais devem ser temidas que desejadas. A dizer a verdade, estes índios saem da floresta sem nada, «pelados»; daí que nós devemos ajudá-los em tudo, até quando o trabalho lhes proporcione roupas e alimento. Atualmente, se as famílias chegarem aos poucos, em nossa pobreza e pequenez, podemos atender às suas necessidades e à sua instrução, o que não seria possível se viessem em grande número. (Merlatti, 200I: 35-36)

Frei Celso não escondia que os missionários passavam por situações perigosas e luta diária contra «falsos profetas, caciques e mandões das selvas». Ele devia estar se referindo aos boatos sobre os missionários que eram acusados de quererem roubar as crianças e fazer os índios trabalharem. E também devia referir-se às emboscadas organizadas por líderes indígenas que estavam contrariados com a existência de uma redução (colônia) em seu meio. Na carta dirigida ao seu irmão, padre Manoel, escrita em abril de I899, Celso confessou: «A nossa vida está sempre em perigo» (Arquivo Histórico da Província Nossa Senhora do Carmo, A voz de São Francisco, 1951: 35).

A historiografia capuchinha notificou conflitos entre indígenas e missionários, tentativas de ataque aos frades e ameaças de rebelião. A interpretação é de que os conflitos foram fomentados pelos regatões modernos e outros adversários da missão como maçons e protestantes (Nembro, 1957: II5, I35-I4I)'. Também

Na região amazônica, regatão é o mercador que percorre os rios de barco, parando em vários povoados. No relato dos missionários capuchinhos do século XIX os regatões aparecem como adversários e seu comportamento é repudiado pelos frades: «Os regatões, vinham para nos iludir [na] Missão, e, sob pretexto de hospitalidade, de noite embriagavam os índios para o poder roubar. Mas os índios, instruídos pelos próprios regatões, negavam tudo e diziam que nada havia de mal» (CASTROVALVAS, 2000: 106, grifos no original). Os regatões modernos eram os comerciantes e produtores rurais frustrados em seus negócios de exploração dos indígenas depois que estes passaram a viver 
madre Rubatto, que chegou em Alto Alegre com suas irmãs (em junho de i899), relatou que escutou os próprios indígenas narrarem os desafios que os capuchinhos enfrentavam para realizar a missão (Merlatti, 20or: 27).

De fato, além de relações sociais tensas, não faltavam trabalhos duros que eram enfrentados de sol a sol durante a derrubada da mata e abertura de estradas, construção de estabelecimentos e casas, plantação, cuidados dos animais e outros serviços pesados. Logicamente que os capuchinhos tinham funcionários e contavam com a valiosa ajuda dos indígenas, mas eles tanto gerenciavam como executavam todas as tarefas. Nesse árduo cotidiano, a colaboração dos indígenas deve ter orientado muitos trabalhos de identificação e exploração do território já que eles eram profundos conhecedores da geografia, flora, fauna e navegação nos rios do lugar e faziam questão de transmitir esses saberes de geração em geração (Lopes Filho, 2018: 20-22). Como observou Sérgio Buarque de Holanda (1945: I6), nos caminhos do sertão brasileiro o indígena era o principal iniciador e guia dos colonizadores.

Capuchinhos, indígenas e colonos construíram um significativo patrimônio material: casa dos frades com igreja anexa, casa das religiosas, casa e escola das meninas indígenas, casas de colonos cristãos e indígenas. Vale salientar a racionalização das moradias: foram «construídas com simetria, mais de 40 casas para os índios, bastante confortáveis e sólidas e revestidas de azulejos, o que para os índios é um verdadeiro luxo» (AHPNSC, Annali Francescani, 1920: 309). Também havia fábrica de açúcar, celeiros, ferramentas e equipamentos agrícolas como máquina de empilhar arroz. Notável era a máquina de ferro para espremer cana-de-açúcar: com peso não inferior a $300 \mathrm{~kg}$, foi encomendada por frei Rinaldo e exigiu o trabalho de oito bois e 40 indígenas para transportá-la de Barra do Corda para Alto Alegre (Idem).

Em apenas quatro anos, a colônia caminhava para ser autossustentável por conta de seu rico canteiro de algodão, arroz, feijão, café, cana, mandioca, milho, legumes, hortaliças e frutas.

Onde antes não se viam mais que espinheiros, contemplavam-se plantações de cana-de-açúcar, bananeiras e variadas espécies de plantas frutíferas. A espaços, podiam-se ver largos tratos, cheios de brancos capuchos de algodão. Em lugares mais reservados, canteiros bem protegidos mostravam as qualidades de todo gênero de hortaliças e legumes. (Monza, 20I6: 49)

A colônia também constituía uma fonte de renda com a venda de açúcar, rapadura, farinha e outros produtos para os mercados vizinhos. Toda essa prosperidade se devia às boas condições da terra, investimento tecnológico dos capuchinhos e empenho dos indígenas, que «aprendiam com desenvoltura e inteligência» (AHPNSC, $A$ voz de São Francisco, 1951: 23).

e trabalhar na Colônia de Alto Alegre (Nembro, 1957: 135). Fica em aberto para futuras pesquisas a questão dos capuchinhos lombardos com os maçons do Maranhão. À época da missão em Alto Alegre havia Lojas maçônicas apenas em São Luís e Caxias (Fernandes, 20I6: 47-58). 
Mas havia problemas na criação de bovinos, relatados por frei Celso na mesma carta dirigida ao seu irmão e aludida anteriormente. Embora possuíssem I5o vacas não havia um curral e elas ficavam soltas à mercê de animais predadores e dos próprios indígenas e não indígenas da região. Por esse motivo, os frades só conseguiam criar 50 a 60 bezerros por ano, sendo que precisavam de um boi por semana para abastecer a todas as famílias que residiam na colônia. E mesmo com tantas vacas só conseguiam tomar leite duas vezes por mês. Não há informação se esse problema foi resolvido, mas é notável o fato de que os capuchinhos não possuíam experiência em pecuária, muito diferente da forma que gerenciavam a agricultura e a construção civil na colônia.

No aspecto cultural, além dos afazeres cristãos que ocupavam boa parte do tempo (orações diárias, celebrações dominicais e catequese ministrada três vezes por semana), os capuchinhos organizaram uma escola de alfabetização na colônia: «ensinam-se diariamente as primeiras letras, contas e preceitos de moral e civil educação» (AHPNSC, «Relatório da Missão Capuchinha no Estado do Maranhão I894-1900», Transcrição de Frei Rogério Beltrami, Documento mimeografado, I995, folha 42). Na perspectiva indígena, é provável que a alfabetização representasse uma ocasião para adquirir maior autonomia e assim lidar melhor com os homens da sociedade dita civilizada. Pode-se imaginar o que significou para eles aprender a contar, reconhecer dinheiro, escrever pequenos bilhetes na virada do século xix/Xx. Sabe-se que até a década de 1980 havia indígenas dessa região que eram enganados pelos patrões porque não sabiam contar dinheiro (Lopes Filho, 2018: 27-28).

Uma última questão a ressaltar é o custo social da Colônia de Alto Alegre para a população indígena.

Tal como os aldeamentos dos jesuítas do tempo colonial, analisados por Baêta Neves (1978), tratava-se de um local previamente escolhido para agrupar indígenas independentemente de sua etnia, promovendo a racionalização de suas moradias, trabalho, roupas, uso do corpo e do tempo segundo padrões não indígenas. Tudo isso gerava muita insatisfação e fugas constantes, as quais eram alvo de punição e coerção por parte da guarda indígena constituída pelos capuchinhos.

A Colônia de Alto Alegre tinha ainda outro agravante: a exemplo dos antigos aldeamentos da missão capuchinha no Segundo Império, ela era aberta para as famílias cristãs de Barra do Corda, prática que foi evitada pelos jesuítas e muito criticada pelos estudiosos do período imperial no sentido de ter sido muito nociva à convivência entre indígenas e não indígenas, acarretando uma série de prejuízos para os índios, tais como a contaminação por muitas doenças. (Custódio, 2020: 327)

A configuração da Colônia de Alto Alegre como uma redução acarretou a sua própria destruição e de sua obra mais cara, o instituto de educação para meninas indígenas. 
O INSTITUTO DE ÍNDICAS DE ALTO ALEGRE:

MARIA APARECIDA CORRÊA CUSTÓDIO

\section{O instituto de educação para meninas indígenas (I899-190I)}

Transcorridos três anos, os capuchinhos inauguraram o instituto para meninas indígenas ou «colégio» conforme é identificado na documentação. Havia até uma placa indicando que era uma Escola Indígena (AHPNSC, Annali Francescani, I920: 308).

De fato, foi configurado como um internato feminino ou uma escola-internato. A narrativa dos primórdios dessa instituição tem base histórica, mas a interpretação dos fatos disseminada na documentação capuchinha foca seu olhar nas origens míticas. Nesse sentido, há uma narrativa que pode ser considerada uma espécie de mito fundador do instituto: a história da pequena Josefina que foi deixada na porta da Igreja dos frades.

Era o dia 4 de fevereiro de 1899. [...] Padre Celso abriu a porta da igreja, e grande foi a sua surpresa quando viu a poucos passos dali uma pequena menina selvagem. Ela não haveria de ter mais que dois anos de idade, e seu corpinho estava nu e tão coberto de feridas que causava dó só vê-la no chão. (Monza, 2016: 57)

Josefina foi considerada uma enviada do santo (São José), daí o seu nome de batismo recebido no dia seguinte de sua recepção na Igreja. Ela foi deixada pela mãe porque estava muito doente e corria risco de morte. Era filha de uma mulher de nome Rosa Cunha, da aldeia do Coco. Rosa foi abandonada pelo pai da menina e uniu-se a outro homem, o major Antonino 6 . «Este, vendo a criança doente, fraca, coberta de feridas, sofrendo muito, tinha determinado, segundo o costume de sua tribo, livrar-se dela, matando-a» (Monza, 2016: 58). Apesar da tentativa de Rosa de dar outro destino para sua filha, Josefina não resistiu. Veio a falecer no dia Is de fevereiro de i899. No entanto, sua breve passagem por Alto Alegre chamou muita atenção dos indígenas.

Os selvagens, admirados de tantos cuidados e preocupações exercidos com a inocente selvagem Josefina, começaram a levar ao padre Celso as suas crianças pequeninas, implorando que as recebesse e prometendo que nunca mais as matariam ou exporiam a perigo de morte. (Monza, 2016: 58)

A operacionalização dessa demanda só foi possível graças à divisão sexual do trabalho religioso, considerando que os missionários solicitaram o auxílio das Irmãs Capuchinhas de Gênova ou Capuchinhas de Madre Rubatto como eram

${ }^{6}$ O sistema de nomear os indígenas com títulos de major, capitão, tenente etc. por lideranças externas à aldeia é bastante antigo nas comunidades Tentehar. Fróes Abreu (1931:I22) foi um dos primeiros pesquisadores a publicar dois documentos de nomeação de capitães: um datado de I9I2 e outro de 1919. Wagley e Galvão (I955: 36) confirmaram a observação de Froés Abreu e explicaram que em tese eram atribuídos poderes sobre os índios da aldeia, mas na prática os nomeados não tinham prestígio nem autoridade. $\mathrm{Na}$ mesma linha, o historiador capuchinho comentou que esses títulos «serviram apenas para os índios se exibirem entre seus companheiros e, para o governo, para mantê-los tranquilos» (NemBro, 1957: II8). 
mais conhecidas. Elas eram conterrâneas dos capuchinhos lombardos e seguidoras do mesmo franciscanismo. Após a chegada das missionárias (seis freiras italianas que estavam em Montevidéu e uma postulante brasileira que foi recrutada em São Luís do Maranhão), no dia 2 de julho de 1899 foi inaugurado o Instituto de Índias de Alto Alegre (Nembro, 1957: I2I). O evento reuniu todo o povo da colônia e dos arredores. Da parte dos povos indígenas, a narrativa mostra que as lideranças sentiram-se responsáveis pela representação de seu povo, pois «seus chefes se apresentaram com seus respectivos distintivos de capitães, majores, coronéis, e todos estavam bem vestidos» (Monza, 2016: 70).

Embora o método de recrutamento das crianças tenha sido questionável devido à abordagem invasiva realizada nas aldeias por alguns missionários (Custódio, 2020: 328-329), em julho de 1899 havia cinco meninas. Em outubro, esse número saltou para 25. Em janeiro de I900, chegou-se ao montante de 43 meninas - assim escreveu frei Zacarias de Malegno ao Ministro Provincial, em 26 de janeiro de 1900. Com a morte inesperada de frei Celso, ocorrida em in de novembro de i889, Zacarias passou a ser o diretor da colônia (Merlatti, 20or: 46).

Reunir 43 meninas em menos de um ano de funcionamento do instituto não era um acontecimento comum nas áreas rurais do Brasil profundo. Conjectura-se que o povo Tentehar (maioria na região da Colônia de Alto Alegre) devia valorizar a ocasião de colocar suas filhas em uma instituição onde podiam receber uma educação que lhes possibilitasse construir um conhecimento que naquele tempo não era ministrado nas aldeias, a saber: a escola de alfabetização. Mesmo enfrentando a resistência das meninas, se fosse mesmo como flagrou Fróes Abreu (1931: s. p.) em sua visita à Aldeia Colônia: «Crianças apavoradas com a aproximação de um caraíu [branco]».

Os Tentehar deviam saber que nas instituições capuchinhas podiam aproveitar a oportunidade de estudar como ocorrera com seus parentes na antiga Colônia Dois Braços onde foi registrada a existência de I7 indígenas alfabetizados conforme o relatório do diretor-geral dos índios de 1890 (Gomes, 2002: 222). Nesse aspecto, os Tentehar do Maranhão podem ser comparados com os parentes Tembé do Pará em período simultâneo e sob a ação da mesma Ordem religiosa: eram «sujeitos ativos na relação de contato» e aproveitavam a ocasião para usufruir dos projetos educativos dos capuchinhos (Rizzini e Schueler, 20II: 86-I07). 
O INSTITUTO DE ÍNDICAS DE ALTO ALEGRE:

FIGURA II: Crianças Tentehar (1930)

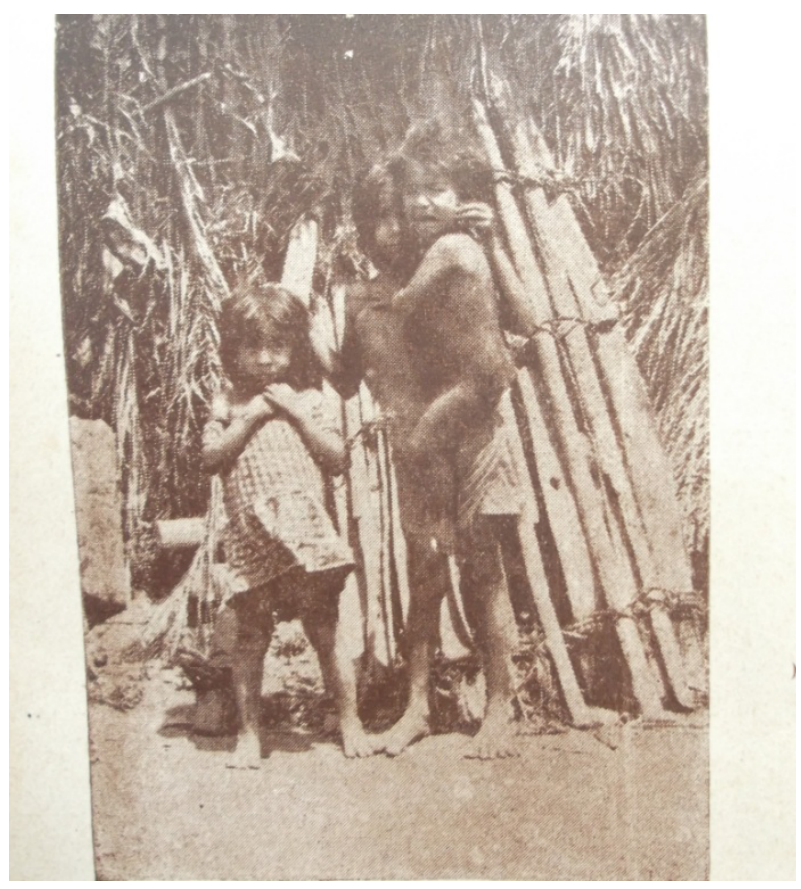

Fonte: Abreu (I93I: s. p.).

Foi assim que eles se submeteram às «Normas para as Reverendas Madres no que diz respeito à educação das meninas indígenas e cristãs pobres» assinadas pelo frei Rinaldo de Paullo (Superior da Missão do Maranhão) em agosto de I899 (AHPNSC, «Prelazia de Grajaú - Índios», Documento sem data; Nembro, 1957: I24-I25; Merlatti, 20oI: 30-32). O documento descreve que o objetivo principal da catequese dos índios era tirá-los do estado pagão e da «vida bruta» para torná-los cristãos capazes de conviver na sociedade civilizada. Sendo assim, o principal objetivo do Instituto de Índias era fazer com que as meninas dessem o primeiro passo entrando na Igreja de Cristo e participando da vida civilizada. Mas essa educação devia efetuar-se de um modo compatível com as condições das meninas: seria ilusório pretender oferecer uma educação avançada que, além de não estar em conformidade com o «pobre estado» dessas garotas, poderia não ser assimilada por elas. A partir do exposto, as freiras deviam ter como meta:

I. Imprimir bem na mente dessas pobres índias a ideia de Deus nosso Criador, de Jesus Cristo nosso Redentor, da vida futura, de um castigo e prêmio eterno.

2. Preparar para o Batismo e outros sacramentos. 
3. Ensinar principalmente o dever de serem boas filhas, esposas fiéis e ótimas mães cristãs.

4. Ensinar ao menos os primeiros rudimentos do conhecimento, como ler, escrever, fazer as contas e outras informações úteis... (Nembro, 1957: 124).

Uma questão difícil é saber que letras foram ensinadas. Imagina-se que devia ser a língua portuguesa, mas não se pode esquecer que as freiras eram italianas e sabiam o espanhol porque estavam em Montevidéu antes de virem para o Brasil. É possível que tenham praticado o portunhol (mistura de palavras da língua portuguesa e da espanhola) enquanto aprendiam a língua portuguesa? Semelhante dificuldade os frades também enfrentaram, mas em relação à mistura da língua portuguesa com a italiana que transparece na escrita da Crônica do Instituto dos Índios (AHPNSC, Crônica do Instituto dos Índios, manuscrito, I894-1900).

As Normas também advertiam as freiras para não acostumarem as meninas a uma vida cômoda e delicada, pois o futuro lhes reservava privações e fadigas (pensamento recorrente na história da educação de crianças pobres). Ao contrário, as meninas indígenas deviam ser educadas para fazerem trabalhos historicamente atribuídos às mulheres pobres.

[...] costurar, cortar roupas femininas e masculinas, lavar, cozinhar e assim por diante. Trabalhar com máquina, bordar, fazer flores de papel e coisas do gênero, são coisas para meninas de alta posição e não para índias pobres: entende-se [porém] que se a idade permitir, elas também podem lidar com isso. (Nembro, 1957: 125)

Nas referidas Normas havia um dispositivo muito estratégico: permitir o ingresso de algumas meninas cristãs ao instituto a fim de mostrar aos indígenas que os missionários procuravam seus filhos somente para educá-los e não para apropriar-se deles. As meninas cristãs deviam pagar io mil réis por mês para custear lavanderia e alimentação, mas roupas e uniforme deviam ser providenciados por suas famílias (Merlatti, 20or: 32). Parece que a proposta foi bem recebida pela comunidade católica, pois cerca de io meninas cristãs foram mencionadas no jornal local (O Norte) por ocasião da rebelião indígena, com destaque para a menina Úrsula Ribeiro que foi resgatada de um acampamento pelos militares que perseguiram os líderes do levante de Alto Alegre.

Vale salienta que além da gerência e docência no Instituto de Índias as capuchinhas abriram uma escola masculina para os filhos dos moradores da colônia (indígenas e não indígenas), satisfazendo assim a uma das finalidades da missão. E ainda ministraram catequese para os adultos e assistiram aos doentes das aldeias, ação que lhes angariou a estima dos indígenas. Em todos esses trabalhos contavam com o apoio de sua madre Rubatto que enviava linhas, agulhas, tesouras, remédios etc. (Merlatti, 200I: 29, 52, 53 e 54). 
O INSTITUTO DE ÍNDICAS DE ALTO ALEGRE:

\section{Práticas educativas controversas}

Em termos pedagógicos, o Instituto de Índias foi organizado com o mesmo formato do instituto masculino de Barra do Corda e reproduziu os mesmos padrões civilizatórios da Colônia de Alto Alegre: racionalização das roupas das meninas, uso do corpo e do tempo segundo padrões não indígenas, aprendizado de práticas domésticas conforme o costume não indígena. Há indícios da questão supracitada em um fragmento da carta de irmã Agnese de S. Carlo, diretora do instituto, dirigida a uma colega que estava em Montevidéu: «Tivemos que usar algumas das nossas saias para vestir as pequenas selvagens... Para acostumá-las à limpeza, é um sacrifício... Nas famílias vivem como pequenos animais...» (Toso, 2002: 238).

Condicionadas pelo quadro de pensamento de sua época, as freiras não conseguiam observar que nas aldeias do povo Tentehar depois dos sete anos a educação das meninas era responsabilidade das mães e das avós. Entendia-se (e entende-se até hoje) que elas deviam ajudar nas tarefas de casa e também aprender como serem boas esposas. Ao completarem oito anos de idade eram ensinadas a trabalhar com o algodão, a fiar, lavar a própria roupa e o calção do irmão, e ajudar a mãe com os trabalhos da casa. Com o tempo, a colaboração das meninas tornava-se muito importante para as mães poderem realizar outros trabalhos como cuidar da roça e produzir artesanatos (Zannoni, I998: 8I e 1999: 6I-63). Com outras palavras, as meninas indígenas não viviam como «pequenos animais» em suas famílias, mas participavam de uma rotina de aprendizados construídos gradativamente.

$\mathrm{Na}$ verdade, as práticas educativas das freiras estavam alinhadas com o eixo catequético-pedagógico do Instituto de Índias e eram condizentes com a política indigenista de época: a catequese e civilização de meninas e adolescentes tinham como objetivo promover a sua integração na sociedade brasileira por meio do ensino da religião, trabalhos domésticos e alfabetização rudimentar. Não se sabe se esse currículo inicial evoluiria caso o instituto prosseguisse com suas atividades por mais tempo, a exemplo do Instituto de Índios de Barra do Corda que mantinha escola primária de acordo com a instrução pública do estado do Maranhão. Mas sabe-se que as meninas Tentehar falavam somente sua língua materna, o que se constituiu um grande entrave para o projeto de formação das freiras. Sem contar que as meninas Tentehar eram maioria, mas não as únicas, pois o instituto agregava indígenas de outras línguas e culturas. Pode-se imaginar a cena bíblica de pentecostes no dia a dia daquele instituto feminino!

Contudo, o maior desafio do Instituto de Índias foi o enfrentamento da epidemia de sarampo a partir de fevereiro de 1900. Houve muita contaminação e mortes, levando em conta as precárias condições sanitárias da época e o fato de a colônia reunir indígenas e não indígenas, submetendo os povos originários a uma situação de vulnerabilidade frente a uma doença facilmente transmissível (o sarampo se espalha pelo ar por gotículas respiratórias produzidas ao tossir ou espirrar). Em Alto Alegre, a epidemia de sarampo levou a óbito 22 meninas do instituto e mais cinco crianças das famílias que residiam na colônia, afetando 
O INSTITUTO DE ÍNDICAS DE ALTO ALEGRE:

MARIA APARECIDA CORRÊA CUSTÓDIO

sobremaneira o desenvolvimento da missão. O instituto transformou-se em enfermaria.

«A nossa casa dentro de poucas horas encheu-se de caboclos - conta Irmã Inez - e todos para ver a própria filha. Para sossegá-los, já que receávamos uma revolta, tivemos que hospedar e manter por dois dias e duas noites as mães das meninas. A nossa residência transformou-se numa verdadeira aldeia; cantavam, bradavam, choravam e nós correndo para junto de uma ou de outra e acariciando-as para que não nos levassem as crianças...».

Somente após ingentes esforços e orações, as Irmãs readquiriram a confiança dos selvagens. E eis reiniciam-se as viagens nas aldeias e são tão mal recebidas que pedem a suspensão temporária de tais visitas às aldeias, pois havia entre os índios quem chorasse e quem ameaçasse. (AHPNSC, A voz de São Francisco, 1951: 36, grifos nossos)

Passada a calamidade vieram os questionamentos a respeito das razões de tantas mortes. A própria madre Rubatto escreveu ao frei Stefano de Sesto S. Giovanni, diretor do Instituto de Índios de Barra do Corda: «A causa maior dessa mortandade não terá sido a falta de remédios e de assepsia?» (Merlatti, 200I: 50). Os indígenas, por sua vez, «ergueram a voz de que o feitiço dos cristãos queria destruir todos os filhos e filhas dos selvagens» (Monza, 20ı6: 86, grifo no original). A questão ficou mais séria ainda quando as lideranças indígenas começaram a acusar os missionários de quererem matar os seus filhos e destruir todas as suas aldeias (Merlatti, 200I: 47). Uma coisa é certa: a epidemia de sarampo marcou a memória Tentehar a ponto de conservarem a narrativa de que os missionários não estavam tratando bem as crianças e elas estavam morrendo. A transmissão dessa memória de geração em geração produziu relatos sincréticos nem sempre condizentes com as práticas educativas dos missionários (Custódio, 2020: 330-33I).

De fato, a morte das meninas acirrou o clima de hostilidade e desconfiança de grande parte dos indígenas para com missionários e missionárias. Nesse contexto outra questão aflorou: a rejeição ao confinamento das meninas, sobretudo, do povo Tentehar. Por que os Tentehar passaram a rejeitar a vida institucionalizada de suas meninas? Para tentar responder a essa questão recorremos aos estudos do sociólogo Claudio Zannoni (I998 e 1999) que conviveu longamente com o povo Tentehar e recolheu suas histórias, memórias e tradições conservadas até os dias de hoje.

A mulher é uma figura forte na sociedade Tentehar, pois é muito importante na organização social, econômica, política e cultural desse povo. Deve ser educada por seus pais e, especialmente, pela avó materna. Porém, toda a comunidade tem o dever de ensinar o que ela precisa aprender ao longo de seu desenvolvimento e também repreender caso seja necessário. Na menarca, marco relevante na trajetória de uma mulher Tentehar, ela precisa passar pelo ritual de reclusão da menina moça, processo pelo qual transforma seu corpo para a vida de mulher. Depois que a menina passa pelo ritual de reclusão e participa de outras etapas da iniciação feminina ela pode constituir família extensa e contribuir com o sustento 
de sua família de origem ${ }^{7}$. Desse modo, ela pode trazer o marido para dentro do grupo familiar de seus pais uma vez que a residência é uxorilocal: o homem se fixa junto do grupo da mulher e representa uma nova força de trabalho, aumentando o poder político e econômico do sogro (Zannoni, I998: I22).

O ritual de iniciação feminina é um tanto complexo e exige a vivência de uma série de pequenos rituais que duram até um ano, sendo acompanhados sistematicamente pelas famílias. A última etapa é a apresentação da menina moça na Festa do Moqueado, que significa literalmente festa de preparação da carne a ser secada em grelha de varas para ser conservada e distribuída aos participantes. No passado a apresentação da menina moça era feita de forma personalizada. $\mathrm{Na}$ atualidade, na Terra Indígena Bacurizinho, a Festa do Moqueado é realizada com a participação de todas as moças que menstruam no mesmo ano por conta de vários motivos entre os quais a escassez da caça e a dificuldade de os indígenas se afastarem do trabalho por vários dias durante o ano (Informação verbal) ${ }^{8}$.

\section{FIgURA III: Festa do Moqueado na Terra Indígena Bacurizinho (20I4)}

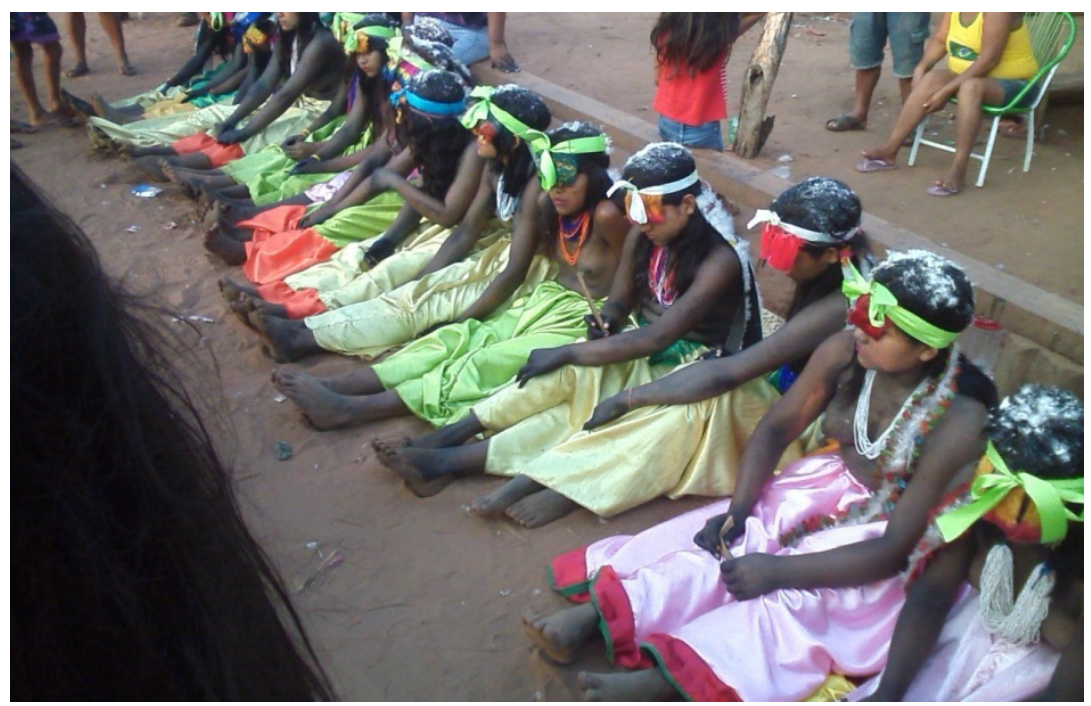

Fonte: Acervo da autora.

Após a Festa do Moqueado a menina moça pode casar e procriar. Como não existe um ritual de casamento entre os Tentehar, se ela tiver sido prometida a um rapaz os pais dele o levam até a casa dos pais dela. Lá eles são abrigados em um

Família extensa é «constituída por um número de famílias simples unidas entre si por laços de parentesco. Esta se constitui a partir do casamento realizado entre as filhas do chefe da família e parceiros de outras famílias» (ZANNONI, I998: I2I).

8 Lopes Filho, A. História de vida. Aldeia Cocal Grande, 20I7. Entrevista. 
quarto até o nascimento do primeiro filho, passando depois a uma casa própria dentro do terreno dos pais da moça. Vale comentar que o universo simbólico do povo Tentehar é povoado de seres espirituais, em especial, os espíritos da floresta e das águas que podem beneficiá-lo ou puni-lo caso não cumpra as regras da comunidade entre as quais o ritual da menina moça. A crença é de que se uma menina não passar pelo ritual de iniciação ela pode ficar doente e até morrer.

Conforme se verifica, a educação Tentehar era muito diferente da educação capuchinha. Na hipótese de Zannoni (1998: 104) a prática de recrutar, educar e manter as meninas reclusas em regime de internato no Instituto de Índias desestruturava a organização social dos Tentehar, pois as meninas aprendiam valores e técnicas diferentes da sua cultura. Além disso, o fato de não poderem realizar o ritual da menina moça deve ter incidido na opção de resgatá-las do instituto, ainda mais no contexto de mortes provocadas pela epidemia de sarampo. É provável que todas essas questões tenham constituído uma das fortes razões que levou o povo Tentehar a liderar a rebelião que pôs fim à colônia e ao instituto de educação para meninas indígenas (Custódio, 2020: 326-334).

A rebelião de Alto Alegre teve início no dia I3 de março de I9o e atingiu a colônia e seu instituto de educação e as fazendas circunvizinhas, pois os indígenas queriam reaver suas meninas e também os territórios que outrora pertenceram aos seus ancestrais. A segunda intenção é apontada por Zannoni (I998) como motivo principal da rebelião. Nesse contexto, os indígenas assassinaram in missionários: Rinaldo de Paullo, Zaccaria de Malegno, Salvatore d'Albino, Vittore de Bergamo, Eleonora de Santo Antonio, Maria Natalina, Eufemia de São João Batista, Benedita de São Luís, Maria de São Lourenço, Agnese de São Carlo e a postulante maranhense Ana Maria, e ainda muitos moradores desse lugar. Essa revolta foi a maior rebelião indígena da história do Brasil no século $\mathrm{xx}$, com centenas de mortos (indígenas e não indígenas). Ela pode ser compreendida como uma ação estratégica sinal do contrapoder do movimento indígena que fez recrudescer a luta histórica contra a opressão de todos os tempos, colocando os indígenas em um lugar de poder ainda que provisório (Custódio, 2020: 334-340).

\section{Observações finais}

A primeira observação diz respeito às finalidades e consequências socioculturais da Colônia de Alto Alegre: cristianizar os indígenas por meio do convencimento, da educação de suas crianças e do trabalho agrícola. De um lado, havia a terrível intenção de desmanchar as sociedades indígenas para realocá-las em uma sociedade cristã pretensamente homogênea, mas aglutinadora de povos de diferentes línguas, culturas e experiências, e famílias cristãs não indígenas. De outro lado, havia a perspectiva de integrar as meninas do Instituto de Índias na sociedade pela via da religião, trabalho doméstico e alfabetização. E integrar meninos e adultos residentes na colônia por meio do ensino de religião, trabalho agrícola e primeiras letras (alfabetização). 
Da parte dos indígenas, são surpreendentes os indícios que mostram a sua engenhosidade ao buscarem educação/escolarização por meio de sua adesão à colônia e ao Instituto de Índias, que representou uma boa tática para conquistarem sua autonomia diante da sociedade não indígena da região de Barra do Corda. Eles fizeram uma capitalização de ganhos muito significativa, a qual imprimiu um legado: os descendentes dos Tentehar que migraram para a Terra Indígena Bacurizinho após a destruição da Colônia de Alto Alegre contam com satisfação sua história de escolarização no colégio capuchinho de Grajaú (Lopes Filho, 20I8: 28).

Não podemos esquecer que a educação escolar foi uma das bandeiras de luta dos movimentos sociais voltados para as minorias raciais do país ao longo de todo o século XX. A área da educação continua a ser uma linha prioritária no roteiro das agendas públicas de muitos Estados americanos comprometidos com as demandas indígenas. Entretanto, as políticas educacionais ainda não atenderam aos anseios mais profundos da população indígena em relação a uma educação que signifique plena consciência da riqueza cultural, ecológica, econômica, política e espiritual dos povos originários (Gómez, Malanda e Fique, 20I8: 149).

A segunda observação é direcionada ao aspecto ideológico da missão, ou seja, a questão da mentalidade dos antigos missionários em relação aos povos indígenas. Os capuchinhos da virada do século XIX/XX demonstravam certo alinhamento com as experiências de aldeamento dos períodos anteriores e com a política indigenista da novel República sendo acompanhados por suas patrícias, as capuchinhas de Gênova. Conforme frei Rogério Beltrami (1925-2020), um dos últimos lombardos que residiam no Brasil, a mentalidade dos capuchinhos começou a mudar somente a partir do Concílio Vaticano II, ou seja, na década de 1960 (Informação verbal)?.

Historicamente a Igreja Católica no Brasil sedimentou uma nova metodologia de trabalho com os povos indígenas por meio do Conselbo Indigenista Missionário (CIMI) que foi criado em 1972 no bojo da opção pelos pobres declarada pela Conferência de Medellín (I968), a qual se deteve na aplicação dos decretos conciliares do Vaticano II na América Latina. A opção de Medellín provavelmente implicou na luta contra o latifúndio na Amazônia e marginalização social a que estava submetida, sobretudo, a população indígena, dando à luz o CIMI. Essa contextualização permite compreender melhor os missionários considerando que as ideias se movem muitas vezes em um tempo de longa duração ainda mais quando os agentes estão posicionados em um lugar próprio e desse lugar operam suas estratégias de comando que muitas vezes entram em conflito com as demandas das classes populares.

9 Beltrami, R. Missão indígena dos capuchinhos lombardos. São Luís, 20I7. Entrevista. 
O INSTITUTO DE ÍNDICAS DE ALTO ALEGRE:

CATEQUESE, INSTRUÇÃO E REINVENÇÃO INDÍGENA (MARANHÃO, SÉCULO XIX/XX)

MARIA APARECIDA CORRÊA CUSTÓDIO

\section{Referências}

Abreu, S. F.: Na terra das palmeiras, Rio de Janeiro, Officina Industrial Graphica, I93I.

Arquivo Histórico da Província Nossa Senhora do Carmo: Cronica do Instituto dos Índios, Barra do Corda, Manuscrito, I894-1900.

AhPnsc: Annali Francescani, n. 51, Milano, 1920, pp. 307-310.

AhpNsc: "A voz de São Francisco", n. I3, Fortaleza, 1951, pp. I-40.

AhPNSC: «Prelazia de Grajaú - Índios», Manuscrito, sem data e sem página.

Ahpnsc: «Relatório da Missão Capuchinha no Estado do Maranhão I894-190o», Transcrição de Frei Rogério Beltrami, Mimeografado, 1995, p. 42.

Castrovalvas, F. P.: O Rio Tapajós, os capuchinhos e os indios Mundurucus (I871-I883), São Luís, Província Nossa Senhora do Carmo, 2000.

Custódio, M. A. C.: «Missão capuchinha e resistência Tentehar: releituras do Conflito de Alto Alegre», Cadernos de Pesquisa, v. 50, n. 175 (2020), pp. 316-342.

De Certeau, M.: A invenção do cotidiano - artes de fazer, Petrópolis, Vozes, 2009.

Fernandes, J.: A maçonaria no Maranbão, São Luís, Edição do autor, 2016.

Gomes, M. P.: O indio na história - o povo Tenetehara em busca da liberdade, Petrópolis, Vozes, 2002.

Holanda, S. B. de: Monções, Rio de Janeiro, Casa do Estudante do Brasil, 1945.

Instituto Socionmbiental: «Povos indígenas no Brasil - Ganajajara». Disponível em: <https://pib.socioambiental.org/pt/Povo:Guajajara>. Acesso em ro/o7/2020.

Instituto Socioambiental: "Povos indígenas no Brasil - Timbira». Disponível em: <https:// pib.socioambiental.org/pt/Povo:Timbira>. Acesso em 15/07/2020.

Lopes Filho, A.: História de vida de uma liderança Tentehar-Guajajara na Terra Indígena Bacurizinho (Aldeia Cocal Grande, Grajaú - Maranhão), Monografia (Graduação em Pedagogia), Universidade Federal do Maranhão, Imperatriz, 2018.

Meireles, M.: História da Arquidiocese de São Luís do Maranbão, São Luís, Editora da Universidade Federal do Maranhão, 1977.

Merlatti, G.: Amor e martírio em Alto Alegre I90I-200I, Imperatriz, Ética, $200 \mathrm{I}$.

Monza, F. B de: O massacre de Alto Alegre, Brasília, Senado Federal, 2016.

Nembro, F. M.: I cappuccini nel Brasile: missione e custodia del Maranhão (1892-1956), Milano, Centro Studi Cappuccini Lombardi, I957.

Orozco Gómez, M. L.; Fernández Malanda, M. D. e Robayo Fique, N. D.: «Indigenismo, educación colonial y etnoeducación», Historia de la Educación, n. ${ }^{\circ} 37$ (2018), pp. I45-164.

Rizzini, I. e Schueler, A.: «O Instituto do Prata: índios e missionários no Pará (I898-I92I)», Currículo sem Fronteiras, v. II, n. 2 (2011), pp. 86-107.

Toso, R.: Uma mulher forte - Madre Francisca Rubatto, Imperatriz, Ética, 2002.

Wagley, C. e Galvão, E.: Os indios Tenetehara - uma cultura em transição, Rio de Janeiro, Imprensa Nacional, 1955.

Zannoni, C.: Manipulação do conflito pelos Tenetehara do Maranbão, Dissertação (Mestrado em Sociologia), Universidade Estadual Paulista Júlio de Mesquita Filho, Araraquara, 1998.

Zannoni, C.: Conflito e coesão - o dinamismo tenetehara, Brasília, Conselho Indigenista Missionário, 1999. 
